Poster Section

\title{
Highly diluted compounds effects on B16-F10 melanogenesis, reactive species production and tumorigenesis
}

\author{
Francine Bittencourt Potrich, Helisa Helena Wippel, \\ Simone Martins de Oliveira, Dorly de Freitas Buchi, \\ Carolina Camargo de Oliveira, Edvaldo da Silva Trindade
}

Dept. of Cellular and Molecular Biology, Federal University of Paraná, Curitiba, Brazil

\begin{abstract}
Background: Cutaneous melanoma is a highly malignant tumor derived from skin epidermis pigmentproducing melanocytes. During melanin biosynthesis and other tumorigenic process, oxygen and nitrogen reactive species are produced and might be critically involved in melanogenesis. Reactive species play key roles on regulation of many types cell proliferation, including melanoma cells.
\end{abstract}

Aims: We evaluated M8 (Aconitum napellus 20dH, Arsenicum album 18d H, Asa foetida 20dH, Calcarea carbonica 16dH, Conium maculatum 17dH, Ipecacuanha 13dH, Phosphorus $20 \mathrm{dH}$, Rhus toxicodendron $17 \mathrm{dH}$, Silicea 20dH, Sulphur 24dH, Thuja occidentalis 19dH) and M1 (Chelidonium majus 20dH, Cinnamon 20dH, Echinaceae purpurea 20dH, Gelsemium sempervirens $20 \mathrm{dH}$ plus all M8 compounds) effects on cell proliferation, melanogenesis and reactive species.

Methodology: Melanin content was measured in B16-F10 cells after 96 hours of treatment with highly diluted compounds, as well as superoxide anion, hydrogen peroxide and nitric oxide. Furthermore, cell proliferation was investigated by crystal violet and cell viability by trypan blue exclusion method after 48 hours of treatment.

Results: M1 and M8 treatment led to statistically significant increase in B16-F10 melanin content and a decrease in nitrite concentration, a nitric oxide derivative. Superoxide anion and hydrogen peroxide production was not changed, but a decrease in cell proliferation after treatment was observed. NO is known to be involved in tumor progression. NO treated B16-F10 cells exhibited higher metastatic capacity and endogenous NO has antiapoptotic effects. Thereby, low NO levels could account cell proliferation reduction and in vivo tumorigenesis reduction [1]. It is speculated that melanocytes are programmed to survive in order to preserve their photoprotective role, thus in a compensatory manner the cell may synthesize melanin in response to cell proliferation reduction. 
Conclusion: These results suggest that tumorigenesis reduction observed on in vivo models by M8 [1] may be due to changes in cell metabolism as well as in cell proliferation. However further studies are needed to better understand M1 and M8 mechanisms of action.

Keywords: melanoma, melanogenesis, oxygen reactive species

\section{References:}

[1] Guimarães FSF, Andrade LF, Martins ST, Abud APR, Sene RN, Wanderer C, et al. In vivo and in vitro anticancer properties of Calcarea carbonica derivative complex (M8) treatment in a murine melanoma model. BMC Cancer, 2010, 10:113.

\section{(c)) EY-NC-ND Licensed to GIRI}

Support: Fudação Araucária, CNPq and CAPES/REUNI

Conflict of interest: authors declare there is no conflict of interest

Received: 01 June 2012; Revised: 10 August 2012; Published: 30 September 2012.

Correspondence author: Edvaldo da Silva Trindade, edstrindade@yahoo.com.br

How to cite this article: Potrich FB, Wippel HH, de Oliveira SM, Buchi DF, de Oliveira CC, Trindade ES. Highly diluted compounds effects on B16-F10 melanogenesis, reactive oxygen species (ROS) production and tumorigenesis. Int J High Dilution Res [online]. 2012 [cited YYYY Month dd]; 11(40):177-178. Proceedings of the XXVI GIRI Symposium; 2012 Sep 20-22; Florence (Italy). GIRI; 2012; Available from: http://www.feg.unesp.br/ ojs/index.php/ijhdr/article/view/596/592 